\title{
Reparo de fissura de lóbulo auricular usando cola cirúrgica de menor custo
}

\section{Cleft earlob repair by use of low cost surgical glue}

Sandro Cilindro de Souza ${ }^{1}$

Carlos Henrique Briglia ${ }^{2}$

Trabalho realizado no Hospital Geral do Estado da Bahia, Salvador, BA, Brasil.

Artigo submetido no SGP (Sistema de Gestão de Publicações) da RBCP.

Artigo recebido: 24/1/2010 Artigo aceito: $11 / 5 / 2010$

\begin{abstract}
RESUMO
Introdução: As vantagens dos cianoacrilatos em síntese cutânea têm sido sobejamente demonstradas na literatura. Entretanto, estes produtos têm sido subutilizados no Brasil devido aos elevados custos do 2-octilcianoacrilato. Ademais, a forma mais economicamente acessível, o 2-etilcianoacrilato (ECA), tem sido pouco estudada como adesivo cutâneo. Relato do Caso: No caso descrito, os autores relatam a eficiência e as vantagens do fechamento de uma laceração de lóbulo auricular de uma criança usando o ECA de menor custo como alternativa à sutura.
\end{abstract}

Descritores: Adesivos teciduais. Cianoacrilatos. Deformidades adquiridas da orelha. Orelha externa/lesões.

\section{ABSTRACT}

Background: The advantages of the cyanoacrylates in cutaneous synthesis have been frequently shown in the literature. However, these products have not been very used in Brazil due to the high costs of the 2-octilcyanoacrylate. Besides, the form more economically accessible, the 2-etilcyanoacrylate (ECA) has not been much studied as cutaneous adhesive. Case Report: The authors describe the efficiency and the advantages of a laceration closing of a child's earlobe using the low cost ECA as alternative to the suture.

Keywords: Tissue adhesives. Cyanoacrylates. Ear deformities, acquired. Ear, external/ injuries.

\section{INTRODUÇÃO}

Desde o final da década de 50 do século passado, adesivos sintéticos têm sido experimentados para aplicação médica. Atualmente, os mais usados no fechamento cutâneo são os cianoacrilatos. Em uma reação exotérmica espontânea, estas substâncias se polimerizam a partir de um monômero éstercianoacrílico, $\mathrm{CH}_{2}=\mathrm{C}(\mathrm{CN}) \mathrm{COOR}$. A película resultante liga os aderentes como uma ponte. A mais importante característica química dos cianoacrilatos é a capacidade de formar rapidamente uniões fortes que aumentam progressivamente de intensidade nas 48 horas seguintes. Os cianoacrilatos constituem um interessante método de síntese, pois não traumatizam os tecidos e eliminam a necessidade de pontos ${ }^{1}$.

As vantagens dos cianoacrilatos na síntese cutânea têm sido sobejamente demonstradas na literatura ${ }^{2}$. Entretanto, estes produtos têm sido subutilizados devido aos elevados custos do adesivo cirúrgico quase que exclusivamente usado no Brasil atualmente, o 2-octilcianoacrilato. Ademais, a forma mais economicamente acessível, o 2-etilcianoacrilato (ECA, Aron Alpha, Permabond, cola de Krazy; Epiglu ${ }^{\circledR}$ ), tem sido pouco estudada como adesivo cutâneo ${ }^{1-3}$.

No caso descrito a seguir, os autores têm como objetivo evidenciar a eficiência do fechamento de uma laceração de orelha usando o ECA como alternativa à sutura.

\section{RELATO DO CASO}

BEJA, sexo feminino, 5 anos, vítima de queda de uma altura de cerca de um metro e meio, sofreu contusão direta

1. Cirurgião Plástico da Clínica das Faculdades Adventistas da Bahia, Cachoeira, BA, Brasil; Membro Titular da Sociedade Brasileira de Cirurgia Plástica (SBCP).

2. Cirurgião Plástico do Hospital Geral do Estado da Bahia, Salvador, BA, Brasil; Membro Associado da SBCP. 
do pavilhão auricular direito contra o solo, o que resultou em uma ruptura linear de $5 \mathrm{~cm}$ de extensão em lóbulo, estendose em $2 \mathrm{~cm}$ à região da concha, por sobre o meato acústico externo (Figura 1A). As avaliações clínica e neurológica não detectaram anormalidades.

Fez-se a antissepsia da orelha com solução alcoólica de clorexidine a $0,5 \%$, seguida da colocação de campos estéreis descartáveis. As bordas da laceração foram infiltradas com solução de lidocaína $(0,5 \%$, vasoconstritor $1: 100.000 \mathrm{UI})$ apenas suficiente para a passagem de dois pontos de ancoragem na extremidade distal do lóbulo fendido, com o intuito de aproximar e retificar as vertentes da lesão. A hemostasia foi realizada por compressão manual com gaze, durante 2 minutos.

As bordas da ferida foram manualmente justapostas e coladas com o espalhamento de quatro gotas de ECA, de modo a formar dois finos filmes sobrepostos, em uma extensão de cerca de $1 \mathrm{~cm}$ lateralmente à linha de ruptura (Figura 1B). Aguardou-se dois minutos para a polimerização de cada película cianoacrílica, não se permitindo escape dos produtos para dentro da lesão. Não foram utilizadas suturas profundas relaxadoras, antibióticos profiláticos ou curativos. Fotografias digitais foram tomadas para comparação macroscópica. A colagem foi realizada em cerca de 15 minutos.

A paciente recebeu alta hospitalar imediata. A orelha foi reavaliada sete e noventa dias após a cirurgia, atentando-se para o desenvolvimento de inflamação, dermatite de contato, infecção, deiscência, anomalias cicatriciais e necrose. Nenhum destes problemas foi verificado, de modo que os resultados estéticos e funcionais foram considerados excelentes (Figura 2).

\section{DISCUSSÃO}

O ECA como adesivo tissular tem sido usado com resultados satisfatórios em Odontologia, Cirurgia Abdominal,
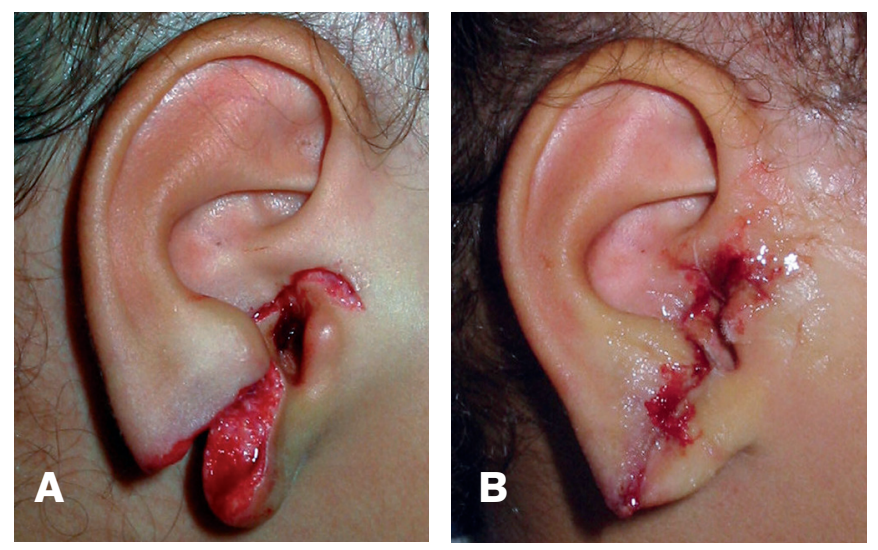

Figura 1-A: Aspecto pré-operatório: ferida contusa linear de espessura total em lóbulo auricular direito. B: Pós-operatório imediato de uso de ECA. O aspecto pontiagudo do lóbulo resultou da tração distal do lóbulo durante o procedimento.
Ginecologia, Gastroenterologia, Neurocirurgia, Cirurgia Maxilar, Ortopedia, Cirurgia Plástica, Urologia, Cirurgia Vascular, Cirurgia Cardíaca, Cirurgia Torácica e Medicina Legal ${ }^{1-6}$. Não obstante, a colagem de lóbulo auricular ainda não tem sido descrita como modalidade de síntese ${ }^{7}$.

Diversos problemas têm sido atribuídos ao ECA como adesivo cutâneo, os quais têm dificultado sua aceitabilidade (Quadro1). O desenvolvimento de sarcomas em ratos após injeção de grandes doses de monômeros de metil-cianoacrilato é a única ligação desses compostos com carcinogênese ${ }^{1}$. Estudos com ECA demonstram que o produto não é carcinogênico ${ }^{5}$. Inflamações agudas e crônicas, seroma, citotoxicidade in vitro, necrose, leuconíquia e dermatite de contato têm sido outros problemas atribuídos ao uso de ECA em pele ${ }^{1}$. No entanto, estes estudos são de pequenas casuísticas, merecendo, assim, avaliações adicionais. Além disso, outros trabalhos têm confirmado que os efeitos desfavoráveis do uso de cianoacrilatos em pele restringem-se a complicações locais discretas, em especial inflamações e deiscências parciais, e são provavelmente devido às próprias cirurgias e não ao uso específico do adesivo ${ }^{2,4,8}$.

Diversos autores têm demonstrado que a principal desvantagem dos cianoacrilatos é a citohistotoxicidade, manifesta por meio de lise celular in vitro e formação de reações inflamatórias agudas ou crônicas in vivo ${ }^{2-5}$. Eles atribuem a toxicidade, sobretudo, à metabolização com liberação de produtos tóxicos. Os derivados de menor cadeia têm mostrado mais histotoxicidade que os de cadeia maior, porque se degradam mais rapidamente. O ECA tem demonstrado evocar menor resposta histotóxica em relação a outros cianoacrilatos de cadeia curta e à sutura ${ }^{4,5}$. A intensidade da inflamação desencadeada pelo cianoacrilato parece não afetar sua força tênsil ${ }^{1}$. O efeito
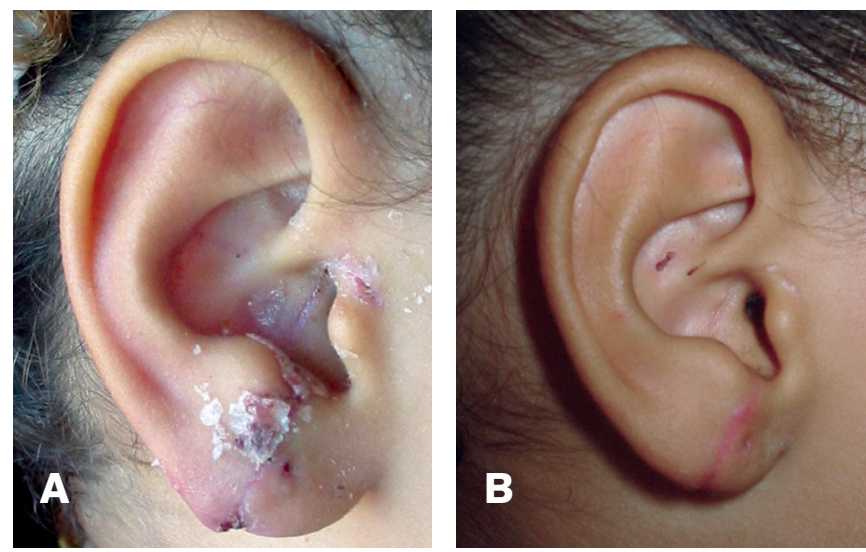

Figura $2-A: 7^{\circ}$ dia pós-operatório. As placas translúcidas são fragmentos residuais de ECA se descolando espontaneamente. B: $90^{\circ}$ dia pós-operatório. Notar cicatriz linear, fina e perfeito alinhamento da borda inferior do lóbulo auricular. 
histotóxico é mais pronunciado em tecidos profundos e bem vascularizados, de modo que o uso de cianoacrilatos tem sido recomendado apenas sobre superfícies avasculares, como a da pele ${ }^{4}$. A despeito dos recentes avanços, o problema persiste de modo que o uso de cianoacrilatos não está isento de $\operatorname{riscos} \cos ^{1,2,9,12}$.

A questão da toxicidade surgiu no meio médico com as aplicações iniciais dos cianoacrilatos na colagem de nervos, tendões, ossos, pulmões, vasos sanguíneos e pele. Trabalhos experimentais sugerem que a necrose induzida pelos cianoacrilatos se restringe à formulação metilcianoacrilato ${ }^{1}$. Entretanto, embora rara, a necrose cutânea é possível ${ }^{9}$.

A deiscência é outra preocupação constante com o uso dos cianoacrilatos. Este problema tem oscilado entre $0,3 \%$ a $26 \%$ e ocorre especialmente em feridas com bordas irregulares ou traumatizadas, em lesões localizadas nas extremidades ou em zonas de pele tensa, sem suturas relaxadoras profundas ${ }^{2,10}$. No presente relato, como o lóbulo auricular se mostrava como zona de pele frouxa, que estava isenta dessas características, e a sua lesão mostrava-se linear, com bordas hígidas, optamos pelo uso do cianoacrilato como primeiro tratamento. $\mathrm{O}$ uso de cianoacrilatos para feridas de alta tensão tem sido limitado, uma vez que esse adesivo consegue força tênsil de uma sutura $5-0^{2,11}$. No presente relato, como o lóbulo auricular se mostrava como zona de pele frouxa que estava isenta destas características e a sua lesão mostrava-se linear com bordas hígidas, optamos pelo uso do cianoacrilato como o primeiro tratamento.

O uso do ECA como adesivo cutâneo tem sido considerado muito seguro. A ausência das mais comprometedoras complicações relacionadas à cicatrização - infecção, necrose, reações alérgicas ou hipertrofia cicatricial - têm sido considerados como os resultados mais animadores de diversos trabalhos ${ }^{1}$. Os baixos índices de infecção têm sido atribuídos à reduzida deposição de corpos estranhos na ferida ${ }^{10}$. As reações alérgicas são raras ${ }^{12}$. O ECA possui qualidades comuns a outros cianoacrilatos, tais como resistência à ação de exsudados, força capaz de suportar até $500 \mathrm{~g}$ de tração, rápida polimerização e efeito selante, bactericida e hemostático ${ }^{5}$. Diversos estudos têm sugerido maior utilização do ECA, a despeito da disponibilidade de outros produtos supostamente menos tóxicos, devido a suas vantagens distintivas sobre os demais cianoacrilatos, como menor custo, rápida degradação e ampla disponibilidade ${ }^{1,3,4}$.

Trabalhos clínicos e experimentais têm sugerido o uso de ECA comercial no fechamento de feridas cirúrgicas em pele ${ }^{1,3,6}$. Neste caso, antes do uso, deve-se tomar especial cuidado na esterilização do ECA. A embalagem deve ser desinfetada com óxido de etileno e confirmada, por meio de culturas, que não apresenta crescimento bacteriano na parte externa ${ }^{6}$. Estudos microbiológicos evidenciam a ausência de proliferação bacteriana no adesivo não esterilizado ${ }^{5}$.

O uso de adesivos cutâneos é particularmente útil em crianças. Em diversos centros pediátricos americanos e europeus, o uso de cianoacrilatos tem sido a primeira escolha no tratamento de feridas contusas em pele ${ }^{8}$. No presente caso, os autores confirmam as vantagens peculiares do uso dos cianoacrilatos, como a dispensa do uso de anestesia, de encaminhamento para centro cirúrgico, de internação e de remoção de suturas, especialmente em face, diminuindo, assim, o estresse dos infantes ${ }^{1,4,8}$.

No presente relato, os cianoacrilatos facilitaram substancialmente o fechamento da lesão auricular. A aplicação do adesivo foi simples, rápida e intuitiva. Polimerizado, o ECA formou sobre a ferida um revestimento flexível, forte e impermeável, prescindindo a remoção de pontos e a colocação de curativos. Isto reduziu a necessidade de cuidados, monitorização e uso de anestésicos, resultando em custos mais baixos. $\mathrm{O}$ produto pode ser até 4 vezes mais barato que a sutura, e 29 vezes que o octilcianoacrilato ${ }^{1}$. A paciente pôde molhar a orelha a partir do dia seguinte ao reparo. O adesivo se soltou completamente, de modo espontâneo, entre 5 a 8 dias. Como dispensou o uso de agulhas, não houve riscos de acidentes de punção. A rápida polimerização do acrilato possibilitou ligação precoce dos tecidos, abreviando o tempo cirúrgico e proporcionando rápida epitelização queratinizada. Estas características têm sido confirmadas pela literatura, de modo que hodiernamente os cianoacrilatos são o método de fechamento de pele que mais agrada aos usuários ${ }^{1,2}$.

Quadro 1 - ECA: vantagens e desvantagens como bioadesivo cutâneo.

\begin{tabular}{l|l}
\hline VANTAGENS & DESVANTAGENS \\
\hline - aplicação rápida e fácil & • pouco estudado \\
- rápido fechamento da pele & • lacrimogênese \\
- menor custo & odor desagradável \\
- dispensa anestesia, curativo & risco de histotoxicidade \\
e retirada de pontos & • risco de reações alérgicas \\
- vasta disponibilidade no & • necessidade de uso de \\
mercado & suturas relaxadoras \\
- profundas \\
reesterilizações e de uso \\
repetido & • uso restrito a feridas \\
- efeito bactericida, & lineares e pouco sangrantes \\
hemostático e selante & \\
- ausência de marcas de & \\
pontos & \\
- excelentes resultados & \\
estéticos & \\
grande satisfação dos & \\
usuários &
\end{tabular}


Estudos clínicos revelam que uso de cianoacrilatos em pele tem resultado em cicatrizes com aspecto estético similar ao de suturas intradérmicas ${ }^{2}$. No presente relato, a aplicação da correta técnica operatória, o uso externo em uma área de pele estática e frouxa, o contato por período curto com a superfície do corpo e a aplicação de mínima quantidade de adesivo foram os fatores atribuídos ao excelente resultado cosmético aos três meses pós-operatórios. Este resultado é preditivo de um ano ${ }^{13}$.

Habitualmente, o tempo total de colagem cutânea é de cerca de 40 segundos a 2 minutos ${ }^{1,2}$. No caso relatado, o tempo total (15 minutos) foi prolongado pela agitação inicial da criança. No entanto, este tempo foi bem menor do que seria necessário se a paciente tivesse sido encaminhada ao centro cirúrgico para a realização de anestesia geral e de sutura.

\section{CONCLUSÕES}

O uso do ECA demonstrou excelente resultado, apresentando uma série de benefícios em relação à sutura. Ademais, devidos a suas vantagens peculiares, este método pode ser a modalidade de escolha quando aplicado no fechamento de fissuras de lóbulo auricular.

\section{REFERÊNCIAS}

1. Souza SC, Oliveira WL, Soares DF, Briglia CH, Athanázio PR, Cerqueira MD, et al. Comparative study of suture and cyanoacrylates in the skin closure of rats. Acta Cir Bras. 2007; 22(4):309-16.

2. Singer AJ, Thode HC Jr. A review of the literature on octylcyanoac- rylate tissue adhesive. Am J Surg. 2004;187(2): 238-48.

3. Borba CC, Roubaud Neto E, Val RLR, Borba Jr CO, Soufen MA, Francisco Neto A, et al. Uso do cianoacrilato na síntese da pele de ratos: trabalho de pesquisa experimental. Acta Cir Bras. 2000;15(1):48-54.

4. Toriumi DM, Raslan WF, Friedman M, Tardy ME. Histotoxicity of cyanoacrylate tissue adhesives. A comparative study. Arch Otolaryngol Head Neck Surg. 1990;116(5):546-50.

5. Montanaro L, Arciola CR, Cenni E, Ciapetti G, Savioli S, Filippini F, et al. Cytotoxicity, blood compatibility and antimicrobial activity of two cyanoacrylate glues for surgical use. Biomaterials. 2001;22(1):59-66.

6. D'Assumpção EA. Cola de cianoacrilato de baixo custo em cirurgia plástica. Rev Soc Bras Cir Plast. 2008;23(1):22-5.

7. Reiter D, Alford EL. Torn earlob: a new approach to management with a review of 68 cases. Ann Otol Rinhol Laringol. 1994; 103(11):879-84.

8. Caloi TM, Manganello-Souza LC. Uso do cianoacrilato no fechamento cutâneo das queiloplastias primárias. Rev Soc Bras Cir Plast. 2005; 20(2):108-11.

9. Wang AA, Martin CH. Full-thickness skin necrosis of the fingertip after application of superglue. J Hand Surg Am. 2003;28(4):696-8.

10. Quinn J, Wells G, Sutcliffe T, Jarmuske M, Maw J, Stiell I, et al. A randomized trial comparing octylcyanoacrylate tissue adhesive and sutures in the management of lacerations. JAMA. 1997; 277(19):1527-30

11. Bernard L, Doyle J, Friedlander SF, Eichenfield LF, Gibbs NF, Cunningham BB. A prospective comparison of octyl cyanoacrylate tissue adhesive (Dermabond) and suture for the closure of excisional wounds in children and adolescents. Arch Dermatol. 2001;137(9):1177-80.

12. Tomb RR, Lepoittevin JP, Durepaire F, Grosshans E. Ectopic contact dermatitis from ethyl cyanoacrylate instant adhesives. Contact Dermatites. 1993;28(4):206-8.

13. Blondeel PN, Murphy JW, Debrosse D, Nix JC $3^{\text {rd }}$, Puls LE, Theodore $\mathrm{N}$, et al. Closure of long surgical incisions with a new formulation of 2-octylcyanoacrylate tissue adhesive versus commercially available methods. Am J Surg. 2004;188(3):307-13.
Correspondência para:
Sandro Cilindro de Souza

BR 101, Km 197, Estrada de Capoeiruçu, s/n, Caixa Postal 18 - Cachoeira, BA, Brasil - CEP 44300-000

E-mail: sandrocilin@hotmail.com 